Syntax Literate: Jurnal Ilmiah Indonesia p-ISSN: 2541-0849

e-ISSN: 2548-1398

Vol. 6, No. 5, Mei 2021

\title{
TERAPI SEFT (SPIRITUAL EMOTIONAL FREEDOM TECHNIQUE) UNTUK MEREDAKAN GANGGUAN CEMAS MENYELURUH PADA SUBJEK DEWASA
}

\section{Karina Kandhi Krisnawardhani dan IGAA Noviekayati}

Fakultas Psikologi Universitas 17 Agustus 1945 Surabaya Jawa Timur, Indonesia

Email : karinakandhi@gmail.com dan ekayatinovi@gmail.com

\section{Abstract}

One specific type recognized by PPDGJ III as an anxiety disorder is generalized anxiety disorder. GAD (generalized anxiety disorder) is an anxiety disorder characterized by a general feeling of anxiety and that something bad is going to happen and a state of increased body arousal. This disorder occurs twice as often in women than in men. People with GAD are chronically anxious. They may worry excessively about their life conditions, such as finances, the well-being of their children, and their social relationships. Other related characteristics are feeling tense, anxious, or worried, tired easily, difficulty concentrating or finding that the mind is blank, irritability, muscle tension, and sleep disturbances (difficulty sleeping, sleeping on, restless and unsatisfactory sleep). This can interfere with individuals in their daily activities. This study aims to intervene in adult subjects who experience a thorough anxiety disorder at uptd Puskesmas Gundih Surabaya. Researchers provide interventions in the form of tapping techniques known as SEFT (Spiritual Emotional Freedom Technique), as a medium to relieve overall anxiety disorders in adult subjects. This therapy is believed to be able to lower anxiety levels. The method used in the study is an experiment with a case study approach. Data analysis in this study uses the integration of all assessment results (observations, interviews and psychological tests), as well as documentation studies. The results of this study showed that SEFT can relieve overall anxiety disorders in adult subjects.

Keywords: $\quad$ Overall anxiety disorder (GAD); SEFT (Spiritual Emotional Freedom Technique)
Abstrak
Salah satu tipe spesifik yang diakui oleh PPDGJ III sebagai salah satu gangguan kecemasan adalah gangguan kecemasan menyeluruh atau generalized anxiety disorder. GAD (generalized anxiety disorder) yaitu suatu gangguan kecemasan yang ditandai dengan perasaan cemas yang umum dan bahwa sesuatu yang buruk akan terjadi dan keadaan peningkatan keterangsangan tubuh. Gangguan ini muncul dua kali lebih banyak pada perempuan dibandingkan pada laki-laki. Orang dengan GAD adalah pencemas yang kronis, mungkin mereka mencemaskan secara berlebihan keadaan hidup mereka, seperti keuangan, kesejahteraan anak-anak, dan hubungan sosial mereka. Ciri lain yang terkait adalah merasa tegang, was was, atau

$\begin{array}{ll}\text { How to cite: } & \text { Krisnawardhani, Karina Kandhi., dan IGAA Noviekayati (2021) Terapi Seft (Spiritual Emotional } \\ & \text { Freedom Technique) Untuk Meredakan Gangguan Cemas Menyeluruh Pada Subjek Dewasa. Syntax } \\ & \text { Literate. 6(5). http://dx.doi.org/10.36418/syntax-literate.v6i5.1952 } \\ \text { E-ISSN: } & \text { 2548-1398 } \\ \text { Published by: } & \text { Ridwan Institute }\end{array}$


khawatir, mudah lelah, sulit berkonsentrasi atau menemukan bahwa pikirannya menjadi kosong, iritabilitas, ketegangan otot, dan adanya gangguan tidur (sulit tidur, tidur terus, tidur yang gelisah dan tidak memuaskan). Hal tersebut dapat mengganggu individu dalam beraktivitas dalam kesehariannya. Penelitian ini bertujuan untuk melakukan intervensi pada subjek dewasa yang mengalami gangguan cemas menyeluruh di UPTD Puskesmas Gundih Surabaya. Peneliti memberikan intervensi berupa teknik tapping yang dikenal dengan SEFT (Spiritual Emotional Freedom Technique), sebagai media untuk meredakan gangguan cemas menyeluruh pada subjek dewasa. Terapi ini diyakini mampu menurunkan tingkat kecemasan. Metode yang digunakan dalam penelitian adalah eksperimen dengan pendekatan studi kasus. Analisis data dalam penelitian ini menggunakan pengintegrasian semua hasil assesment (observasi, wawancara dan tes psikologi), serta studi dokumentasi. Hasil dari penelitian ini menunjukkan bahwa SEFT dapat meredakan gangguan cemas menyeluruh pada subjek dewasa.

Kata Kunci: Gangguan Cemas Menyeluruh (GAD); SEFT (Spiritual Emotional Freedom Technique)

\section{Pendahuluan}

Kecemasan adalah perasaan takut yang tidak jelas dan tidak didukung oleh situasi. Ketika merasa cemas, individu merasa tidak nyaman, takut atau mungkin memiliki firasat akan ditimpa malapetaka padahal ia tidak mengerti mengapa emosi yang mengancam tersebut terjadi (Diferiansyah, Septa, \& Lisiswanti, 2016). Setiap individu akan memiliki tingkat kecemasannya masing-masing, tingkat kecemasan tersebut bisa dipengaruhi oleh pengalaman, masalah yang sedang dihadapi, lingkungan, pola asuh, dan lainnya. Seseorang yang dapat mengendalikan kecemasan dalam dirinya sendiri akan dapat meredakan kecemasannya dan hal itu tidak berlangsung lama. Seseorang yang kurang dapat mengendalikan kecemasannya, ia akan membutuhkan dampingan atau bantuan orang lain untuk meredakan kecemasannya, dan kecemasan yang dialami akan berlangsung lebih lama.

Seseorang yang mengalami kecemasan berlangsung hampir setiap hari, terjadi lebih dari enam bulan, adanya perubahan perilaku dan keluhan abnormal, maka hal ini termasuk gangguan (Apriliani, 2015). Hal tersebut akan mempengaruhi perilaku, aktifitas kesehariannya serta kesehatan fisik tanpa disadari. Pada umumnya individu tidak akan menyadari bahwa kecemasan yang dialami merupakan gangguan. Keluhan pada umumnya saat individu tersebut datang ke ahli ialah keluhan fisiologis, sehingga ahli (misal: dokter) memeriksa kondisi fisik individu tersebut, namun hasil medis menyatakan individu tersebut baik secara fisiologis. Dari hasil yang didapat tersebut maka individu akan mengevaluasi hasil medis dan menyadari bahwa dirinya sedang mengalami gangguan kecemasan.

Salah satu tipe spesifik yang diakui oleh PPDGJ III sebagai salah satu gangguan kecemasan adalah gangguan cemas menyeluruh atau generalized anxiety disorder. GAD (generalized anxiety disorder) yaitu suatu gangguan kecemasan yang ditandai dengan perasaan cemas yang umum dan bahwa sesuatu yang buruk akan terjadi dan keadaan 
peningkatan keterangsangan tubuh. GAD ditandai dengan kecemasan yang persisten, tidak dipicu oleh suatu objek, situasi atau aktivitas yang spesifik, tetapi lebih merupakan apa yang disebut Freud dengan "mengambang bebas" (free floating). GAD merupakan suatu gangguan yang stabil, muncul pada pertengahan remaja sampai pertengahan umur dua puluhan tahun dan kemudian berlangsung sepanjang hidup (Nevid, Rathus, \& Greene, 2005).

Gangguan ini muncul dua kali lebih banyak pada perempuan dibandingkan pada laki-laki (Nevid et al., 2005). Orang dengan GAD adalah pencemas yang kronis, mungkin mereka mencemaskan secara berlebihan keadaan hidup mereka, seperti keuangan, kesejahteraan anak-anak, dan hubungan sosial mereka (Akbar, 2018). Ciri lain yang terkait adalah merasa tegang, was was, atau khawatir, mudah lelah, sulit berkonsentrasi atau menemukan bahwa pikirannya menjadi kosong, iritabilitas, ketegangan otot, dan adanya gangguan tidur (sulit tidur, tidur terus, tidur yang gelisah dan tidak memuaskan) (Nevid et al., 2005). Meskipun GAD secara tipikal kurang intens dalam respon fisiologisnya dibanding gangguan panik, distress emosional yang diasosiasikan dengan GAD sering ada bersama dengan gangguan lain seperti depresi atau gangguan kecemasan lainnya seperti agoraphobia dan obsesif-kompulsif.

Dari permasalahan yang muncul di atas maka peneliti merujuk pada penelitian yang dilakukan (Reeves \& Rowe, 2002) Jack Rowe, Phd. Psikolog dari Texas A \& M University, Kingsville dalam jurnal Counseling \& Clinical Psychology (2015) membuktikan bahwa efek pelatihan EFT tidak hanya jangka pendek, tetapi tetap bertahan dalam jangka panjang dalam penurunan signifikan tingkat stress. Selain itu penelitian yang dilakukan (Suherni; Hidayati, F., 2017), MA tahun 2017 (Fakultas Psikologi Universitas Islam Negeri Maulana Malik Ibrahim Malang) menunjukkan bahwa adanya pengaruh terapi Spiritual Emotional Freedom Technique (SEFT) terhadap penurunan kecemasan.

Penelitian di atas dapat menjadi rujukan atau tambahan bagi referensi peneliti dalam melengkapi data-data yang diperlukan. Kesamaan dengan penelitian terdahulu adalah sama-sama menggunakan teknik Spiritual Emotional Freedom Technique (SEFT) untuk meredakan gangguan kecemasan. Perbedaan dengan penelitian yang dilakukan oleh Jack Rowe, Phd. Psikolog dari Texas A \& M University, Kingsville dalam jurnal Counseling \& Clinical Psychology (2015) ialah dalam penelitian ini ada penambahan spiritual (doa) merupakan teknik tambahan dalam melakukan EFT. Sedangkan perbedaan dengan penelitian yang dilakukan oleh (Suherni; Hidayati, F., 2017), MA tahun 2017 (Fakultas Psikologi Universitas Islam Negeri Maulana Malik Ibrahim Malang) ialah dalam penelitian ini menggunakan studi kasus dan hanya menggunakan satu subjek, sedangkan penelitian (Suherni; Hidayati, F., 2017), MA dilakukan secara klasikal dan intervensi dilakukan dengan pengelompokkan subjek di lembaga pemasyarakatan. Ke khasan dalam penelitian ini adalah intervensi yang dilakukan hanya pada klien dengan gangguan kecemasan menyeluruh (GAD).

Spiritual Emotional Freedom Technique (SEFT) merupakan suatu metode baru dalam melakukan EFT (Rowe, 2005). SEFT adalah salah satu varian dari satu cabang 
ilmu baru yang dinamai Energy Psychology. Energy Psychology adalah seperengkat prinsip dan teknik memanfaatkan sistem energi tubuh untuk memperbaiki kondisi pikiran, emosi dan perilaku. SEFT merupakan gabungan antara Spiritual Power dan Energy Psychology (Zainuddin, 2006).

Spiritual Emotional Freedom Technique (SEFT) bekerja dengan prinsip yang kurang lebih sama dengan acupunture dan acupressure (Rofacky \& Aini, 2015). Teknik ini memiliki 12 jalur energi (the main meridian channels).

Cara Melakukan SEFT ialah langkah pertama (the set-up), kedua (the tune-in beserta kata pengingatnya atau doa: "saya ikhlas, saya pasrah", serta sebagian langkah ke tiga (the tapping), mulai dari titik pertama (the crown) hingga titik ke-9 (bellow nipple). Cukup sampai situ dan akhiri dengan tarik nafas panjang dan hembuskan.

Peneliti menggunakan teknik Spiritual Emotional Freedom Technique (SEFT) dengan alasan tidak membutuhkan waktu lama untuk intervensi dan melihat adanya perubahan perilaku, selain itu terapi menggunakan teknik Spiritual Emotional Freedom Technique (SEFT) ini cukup sederhana, dapat diterapkan pada subjek dengan gangguan cemas menyeluruh, serta dapat diterapkan secara mandiri oleh subjek. Teknik ini juga memiliki tujuan untuk memperbaiki kondisi pikiran, emosi dan perilaku. Sedangkan tujuan utama dalam melakukan intervensi pada penelitian ini adalah agar subjek mampu mengatasi kecemasannya dan meredakan kecemasan yang dialami.

Dari penjelasan di atas maka diyakini bahwa teknik Spiritual Emotional Freedom Technique (SEFT) dapat meredakan gangguan cemas menyeluruh pada subjek dewasa. Penelitian ini diharapkan dapat digunakan sebagai referensi terbaru dalam hal penggunaan terapi dengan teknik Spiritual Emotional Freedom Technique (SEFT) pada subjek dewasa dengan gangguan kecemasan menyeluruh atau GAD. Penelitian ini diharapkan dapat memberikan kontribusi bagi pengembangan keilmuan psikologi, terutama dalam bidang psikologi klinis dan psikoterapi. Selanjutnya penelitian ini dapat menambah skill individu dalam penerapan teknik Spiritual Emotional Freedom Technique (SEFT) saat mengalami gangguan kecemasan menyeluruh (GAD). Selain itu, penelitian ini juga sebagai tambahan informasi bagi pembaca mengenai alternatif untuk penanganan gangguan kecemasan menyeluruh yang dapat berdampak pada psikologis maupun fisiologis, serta mengganggu aktivitas keseharian.

\section{Metode Penelitian}

Penelitian ini menggunakan metode eksperimen dengan jenis pendekatan studi kasus. Eksperimen merupakan metode suatu penelitian yang dilakukan dengan pemberian manipulasi atau perlakuan secara sengaja oleh peneliti yang bertujuan untuk mengetahui akibat manipulasi atau perlakuan terhadap perilaku individu yang diamati. Studi kasus termasuk penelitian analisis deskriptif (Sugiyono, 2015), yaitu penelitian yang dilakukan terfokus pada suatu kasus tertentu untuk diamati dan dianalisis secara cermat sampai tuntas. Dengan demikian metode eksperimen menggunakan pendekatan studi kasus akan dapat menghasilkan data yang lebih lengkap, lebih mendalam, dan bermakna sehingga tujuan dari penelitian ini akan tercapai (Siyoto \& Sodik, 2015). 
Alat yang digunakan dalam pengambilan data dan intervensi adalah kertas HVS (ukuran folio), pensil, ballpoint, clipboard tatakan kertas (papan dada), alat-alat tes psikologi (grafis, WAIS, TAT, Rorschach, HARS), buku catatan, dan map plastik. Subjek dari penelitian ini adalah salah seorang pasien rawat jalan di UPTD Puskesmas Gundih Surabaya berinisial ASB, berjenis kelamin perempuan dan berusia 25 tahun (dewasa). Dari studi dokumentasi di UPTD Puskesmas Gundih Surabaya, serta hasil asessment yang dilakukan oleh peneliti, subjek didiagnosa mengalami gangguan cemas menyeluruh.

Pengambilan data pada penelitian ini dilakukan selama sepuluh sesi pertemuan, dengan rincian empat sesi pertemuan assesment dan enam sesi pertemuan intervensi. Assesment yang dilakukan dalam penelitian ini adalah observasi, wawancara, tes psikologi, dan studi dokumentasi.

Observasi yang dilakukan dalam penelitian ini ialah mendeskripsikan lokasi lingkungan subjek baik saat berkunjung ke UPTD Puskesmas Gundih maupun lingkungan alamiah subjek yaitu tempat tinggal subjek, selain itu peneliti juga melakukan pengamatan umum mengenai perilaku yang dimunculkan subjek, gejalagejala yang nampak merujuk pada PPDGJ III (F20.1) (Maslim, 2013).

Wawancara dilakukan secara informal menggunakan pedoman umum. Wawancara dilakukan pada subjek, keluarga, dokter, dan perawat. Hal ini dilakukan guna mendapatkan data yang lebih detail mengenai kondisi subjek. Selain itu dilakukan wawancara secara mendalam agar dapat mengetahui psikopatologi dan riwayat hidup subjek.

Pengambilan data lainnya menggunakan tes psikologi. Alat tes psikologi yang digunakan peneliti adalah grafis, WAIS, TAT, Rorschach, HARS. Tujuan dari psikotes adalah untuk memperkuat hasil observasi, wawancara, serta dokumentasi untuk mengungkapkan gambaran diri, aspek kognitif, kondisi emosi, sosial, dan tanda-tanda psikologis secara lebih valid.

Analisis data dalam penelitian ini menggunakan pengintegrasian semua hasil assesment (observasi, wawancara dan tes psikologi), serta studi dokumentasi. Hal ini digunakan dalam menegakkan diagnosis, kemudian menentukan dan memberi intervensi yang tepat pada subjek.

\section{Hasil dan Pembahasan}

Subjek merupakan perempuan dewasa berusia 25 tahun. Subjek merupakan anak ke dua dari dua bersaudara. Sejak kecil subjek tinggal dengan ayah, ibu, kakak kandung, tante dan sepupu dalam satu rumah namun hanya memiliki dua kamar (satu kamar kecil dan satu lagi kamar yang cukup luas). Ayah subjek sering bekerja di luar rumah hingga tidak pulang dan ibunya di rumah. Menurut ASB ibunya sangat tempramen dan mudah marah. Saat kecil ASB sering dipukuli, ia mengaku saat kecil bila tidak mau makan ASB dibekap menggunakan bantal hingga tidak dapat bernafas, jika melakukan kesalahan selalu dipukul dengan benda yang ada (apapun itu benda terdekat dengan posisi ibunya). ASB sering melihat pertengkaran antara ibu dan ayahnya, selain itu ia 
sering melihat ibunya memukuli kakaknya yang autis. Ibunya sering menuntut ASB untuk dapat melakukan hal yang ibunya inginkan dan tak peduli ASB suka atau tidak.

Menginjak usia 12 tahun ibu ASB meninggal dunia karena sakit komplikasi. Pola asuh ayah ASB cenderung demokratis dimana ayahnya membebaskan cara berpakaian dan memilih teman namun ayah ASB tidak lepas kontrol atas perilaku putrinya. Secara tidak sadar masih ada kehidupan magis yang dialami subjek, dimana secara tidak sengaja ia dapat melihat kejadian yang akan datang yang akan dialami seseorang.

Pada usia 20 tahun ASB menikah dengan F yang berusia 31 tahun. Pernikahan mereka berjalan 6 bulan, dan mengalami masalah. Dimana F dikeluarkan dari kerjaannya. Beberapa usaha dilakukan namun gagal (tidak kembali modal). ASB hanya diberi uang jajan per hari Rp. 10.000,- oleh F. Uang jajannya dibelanjakan dan untuk masak di rumah. F suka berfoya-foya dengan berbelanja baju untuk dirinya sendiri, menonton konser, mabuk-mabukan dengan teman-temannya dan hal lain. Pada saat ASB berusia 21 tahun kakak kandung ASB meninggal dunia karena panas dan kejang terus menerus. Penderita GAD menuturkan mengalami lebih banyak pascatrauma yang mencakup kematian.

Setiap individu memiliki tingkat kecemasan masing-masing dan cara meredakannya. Namun jika individu tersebut tidak dapat mengatasi kecemasan akan muncul gejala-gejala yang mengganggu. Salah satu gangguan cemas yang dialami individu ialah gangguan cemas menyeluruh. Dimana individu yang mengalaminya akan mengalami gejala-gejala kecemasan, ketegangan motorik, dan overaktivitas otonomik. Seperti yang sedang dialami ASB, ia sering merasa dadanya berdebar, menangis tanpa sebab, kekakuan pada beberapa bagian tubuh (utamanya tangan dan jarinya), susah tidur, tidak nafsu makan dan merasa tidak bahagia. Hal tersebut juga mengindikasikan subjek mengalami kecemasan berat sekali. GAD muncul pada pertengahan remaja sampai pertengahan umur dua puluhan tahun dan kemudian berlangsung sepanjang hidup (Nevid et al., 2005). Melalui rasa khawatir, orang-orang yang menderita GAD menghindari berbagai citra yang tidak mengenakkan dan sebagai konsekuensinya kecemasan yang mereka rasakan.

F tidak bekerja. ASB lah yang memenuhi kebutuhan rumah tangga dengan cara berjualan secara online. Dokter puskesmas menyatakan bahwa ASB ini mengalami masalah kesehatan jiwa, dan kekakuan yang sering di derita ASB berasal dari psikisnya bukan dari pola makan atau hal lain. Hasil pemeriksaan laboratorium juga menyatakan bahwa tidak ada masalah (semuanya normal). Konselor puskesmas kembali memberi konseling pada ASB dan melakukan terapi (empat kali pertemuan). ASB merasa tidak nyaman dengan lingkungannya dan tertekan, sekujur tubuhnya kaku, kaki dan tangannya tidak dapat bergerak, bahkan ia tidak dapat membuka mulutnya. Dokter yang memeriksa ASB menjelaskan ke ayahnya jika hal ini terjadi bisa saja karena ada gangguan psikis.

Orang-orang yang menderita GAD sering kali salah mempersepsikan kejadiankejadian yang biasa. Perhatian para penderita GAD mudah terarah pada stimulus yang 
mengancam. Sensitivitas pasien GAD yang sangat tinggi terhadap stimulus, tidak dapat diterima secara sadar (Blackburn, Davidson, \& Kendell, 1994).

Februari 2019 B (teman lama ASB) mulai mengirim pesan ke ASB, B mengajak bertemu ASB berdua, terjalin komunikasi yang lebih intens. ASB sudah mulai merasa nyaman dengan B. Terjadilah pertengkaran hebat. September 2019 B dan ASB pun melakukan hubungan seksual. September 2019 akhir ASB hamil 2 minggu. Ia meminum jamu-jamuan yang pada akhirnya membuatnya keguguran.

Saat ini ASB merasa sudah tidak ada hati dengan suaminya, merasa hubungan pernikahan mereka hambar dan bahkan saat berhubungan badan dengan suaminya ia merasa biasa saja. ASB bingung jika melanjutkan sama dengan ia menyiksa perasaannya, jika tidak juga dia tidak tau seperti apa.

Berdasarkan hasil assesment psikologi didapatkan hasil bahwa taraf kecerdasan ASB tergolong rata-rata. Subjek mampu menyelesaikan tugas yang sederhana, namun kurang mampu menyelesaikan masalah konkrit. Subjek memiliki indikasi gangguan konsentrasi karena adanya kecemasan. Subjek mengalami kecemasan berat sekali. Secara tidak sadar masih ada kehidupan magis yang dialami Subjek.

Subjek memiliki pikiran yang kacau, kurang sistematis dan emosi tidak stabil, hal tersebut berpengaruh pada pola hidupnya. Subjek lebih dikuasai emosi, sehingga ketika menghadapi permasalahan subjek cenderung agresif, namun ia berusaha sungguh-sungguh menekan impuls agresinya (subjek mampu melakukan kontrol terhadap impuls-impuls dan emosinya). Selain itu subjek mempunyai kontrol atas ekspresi emosionalitasnya yang impulsif. Dimana subjek mampu memberi respon secara proporsional dan wajar, baik dalam perasaan maupun tindakan terhadap lingkungan sosialnya. Subjek memiliki kontrol diri berlebihan sehingga daya tanggap, fleksibilitas, dan daya imajinatif dalam hubungan interpersonal menjadi terganggu.

Subjek memiliki kemampuan yang cukup dalam penyesuaian diri dimanapun ia berada hal ini didukung dengan kemampuan verbal yang dimiliki subjek cukup baik, namun disaat tertentu subjek kurang mampu mengendalikan perilakunya. Subjek memiliki kecenderungan menyibukkan diri di luar rumah, dan memiliki perhatian lebih besar pada keadaan di luar keluarganya. Subjek lebih mengandalkan faktor-faktor dari lingkungan daripada faktor-faktor di dalam dirinya dalam berperilaku mencari kenyamanan atau kesejahteraan dan stimulasi bagi dirinya.

Adanya perasaan insecure, hal tersebut membuat subjek memiliki perasaan bermusuhan dan terancam. Fungsi ayah sangat kabur. Subjek merasa menderita, kesepian, dan tidak berdaya karena tidak ada dukungan, bantuan, perlindungan dan cinta dari orang lain. Hal tersebut membuat subjek memiliki kebutuhan afeksi. Namun subjek memiliki kecenderungan menolakan, merepresi, atau kurang berkembangnya kebutuhan akan afeksi. Penolakan atau kurangnya kesadaran dan penerimaan terhadap kebutuhan afeksi ini menghambat perkembangan kepribadian. Sehingga kebutuhan afeksi subjek dipenuhi dengan melakukan perilaku yang dilarang, melanggar aturan moral dan standar sosial dengan melakukan hubungan terlarang. Dari perilaku tersebut subjek merasa jatuh cinta juga dicintai oleh orang lain. 
Dalam mengambil keputusan subjek butuh banyak dukungan. Selain itu juga dalam menyelesaiakan permasalahan atau pengambilan keputusan subjek cenderung meminta bantuan, ia membutuhkan dukungan dan nasehat, terkadang ia cenderung menangis dalam memikirkan permasalahan yang ia hadapi.

Subjek memiliki kebutuhan bekerja untuk mencapai suatu tujuan dengan tidak menyerah hingga bisa atau mencapai tujuan yang diinginkan. Namun di sisi lain subjek memiliki minat terhadap lingkungan yang sempit sehingga ia memiliki indikasi keterbatasan dalam efisiensi fungsi intelektual. Subjek memiliki indikasi ambisi yang berlebihan, namun potensi kreatif (sumber produktif) subjek rendah. Hal ini dikarenakan kurangnya dukungan lingkungan yang mempengaruhi pertumbuhan potensi kreatif secara optimal.

Subjek memiliki kebutuhan untuk memberikan kenyamanan dan ketenangan pada orang lain, maka ia membutuhkan situasi baru. Hal tersebut ditunjukkan dengan adanya kebutuhan mengabaikan atau menolak orang lain, untuk menghindarkan diri dari situasi yang membahayakan (hati-hati). Jika hal tersebut dilakukan maka subjek akan dapat menciptakan sesuatu menjadi susunan baru, serta memperbaiki kesalahannya. Subjek juga memiliki kebutuhan memperbaiki kesalahan, dan mengatasi kelemahannya.

Berdasarkan hasil tes psikologi yang diberikan pada subjek, gangguan yang muncul, dan karakteristik perilaku yang muncul dikaitkan dengan Pedoman Penggolongan dan Diagnosis Gangguan Jiwa III (PPDGJ-III), subjek mengalami gangguan cemas menyeluruh. Kriteria diagnosis gangguan cemas menyeluruh menurut PPDGJ-III, sebagai berikut:

Tabel 1

Kriteria diagnosis gangguan cemas menyeluruh menurut PPDGJ-III

\begin{tabular}{|c|c|c|c|c|}
\hline No & Kriteria & Sesuai & Tidak & $\begin{array}{c}\text { Gejala yang Ada pada } \\
\text { Subjek }\end{array}$ \\
\hline 1. & $\begin{array}{l}\text { Penderita harus menunjukkan anxietas } \\
\text { sebagai gejala primer yang berlangsung } \\
\text { hampir setiap hari untuk beberapa } \\
\text { minggu sampai beberapa bulan, yang } \\
\text { tidak terbatas atau hanya menonjol } \\
\text { pada keadaan situasi khusus tertentu } \\
\text { saja (sifatnya "free floating" atau } \\
\text { "mengambang") }\end{array}$ & $\checkmark$ & & $\begin{array}{l}\text { Perasaan khawatir, gelisah, } \\
\text { tidak tenang, adanya firasa } \\
\text { buruk, takut akan pikiran } \\
\text { sendiri, hal tersebut } \\
\text { berlangsung setiap hari. }\end{array}$ \\
\hline 2. & $\begin{array}{l}\text { Kecemasan (khawatir akan nasib } \\
\text { buruk, merasa seperti diujung tanduk, } \\
\text { sulit konsentrasi, dsb) }\end{array}$ & $\checkmark$ & & $\begin{array}{l}\text { Khawatir akan masa depan } \\
\text { sulit berkonsentrasi, daya } \\
\text { ingat menurun. }\end{array}$ \\
\hline 3. & $\begin{array}{l}\text { Ketegangan motorik (gelisah, sakit } \\
\text { kepala, gemetaran, tidak dapat santai) }\end{array}$ & $\checkmark$ & & $\begin{array}{l}\text { Gelisah, sering pusing/ } \\
\text { sakit kepala, kaku, kedutan } \\
\text { otot, otot tegang, kepala } \\
\text { terasa berat, jari gemetar, } \\
\text { muka tegang. }\end{array}$ \\
\hline 4. & $\begin{array}{l}\text { Overaktivitas otonomik (kepala terasa } \\
\text { ringan, berkeringat, jantung berdebar- } \\
\text { debar, sesak napas, keluhan lambung, } \\
\text { pusing kepala, mulut kering, dsb.) }\end{array}$ & $\checkmark$ & & $\begin{array}{l}\text { Takikardi (denyut jantung } \\
\text { cepat), dada terasa } \\
\text { berdebar-debar, nyeri pada } \\
\text { dada, rasa tertekan atau } \\
\text { sempit di dada, tercekik, }\end{array}$ \\
\hline
\end{tabular}




\begin{tabular}{|c|c|c|c|c|}
\hline No & Kriteria & Sesuai & Tidak & $\begin{array}{c}\text { Gejala yang Ada pada } \\
\text { Subjek }\end{array}$ \\
\hline & & & & $\begin{array}{l}\text { nafas pendek atau sesak, } \\
\text { perut melilit, gangguan } \\
\text { pencernaan, kembung. }\end{array}$ \\
\hline 5. & $\begin{array}{l}\text { Individu sulit untuk mengendalikan } \\
\text { kecemasan dan kekhawatiran }\end{array}$ & $\checkmark$ & & $\begin{array}{l}\text { Sulit untuk mengendalikan } \\
\text { kecemasan dan } \\
\text { kekhawatiran hingga } \\
\text { akhirnya meminta } \\
\text { pertolongan pada layanan } \\
\text { psikologi di puskesmas. }\end{array}$ \\
\hline 6. & $\begin{array}{l}\text { Kecemasan, kekhawatiran, atau gejala } \\
\text { fisik menyebabkan distress atau } \\
\text { terganggunya fungsi sosial, pekerjaan, } \\
\text { dan fungsi penting lainnya }\end{array}$ & $\checkmark$ & & $\begin{array}{l}\text { Kekakuan otot akibat } \\
\text { kecemasan terus menerus, } \\
\text { menurunnya daya ingat } \\
\text { sehingga mengganggu } \\
\text { aktivitas subjek. }\end{array}$ \\
\hline 7. & $\begin{array}{l}\text { Gangguan tidak berasal dari zat yang } \\
\text { memberikan efek pada fisiologis } \\
\text { (memakai obat-obatan) atau kondisi } \\
\text { medis lainnya (seperti hipertiroid) }\end{array}$ & $\checkmark$ & & $\begin{array}{l}\text { Subjek tidak menggunakan } \\
\text { obat-obatan yang memberi } \\
\text { efek pada fisiologis, namun } \\
\text { tetap mengalami gangguan } \\
\text { fisik akibat kecemasannya. }\end{array}$ \\
\hline
\end{tabular}

Jika gangguan mental yang dialami subjek disajikan dengan pendekatan multiaxial seperti yang terdapat dalam PPDGJ-III, maka hal itu akan tampak sebagai berikut:

Aksis I : F41.1 (gangguan cemas menyeluruh)

Aksis II : Kepribadian Histrionik

Aksis III : Belum ditemukan

Aksis IV : Masalah dengan "primary support group" dan ekonomi

Aksis V : GAF scale 50 - 41 gejala berat (serious), disabilitas berat.

Berdasarkan riwayat perjalanan kasus subjek, dapat disimpulkan prognosa subjek adalah buruk. Berdasarkan hasil assesment yang dilakukan maka pada kasus ini digunakan teknik Spiritual Emotional Freedom Technique (SEFT) untuk dapat membantu subjek dalam meredakan gangguan cemasan menyeluruh yang dialaminya. SEFT adalah salah satu varian dari satu cabang ilmu baru yang dinamai Energy Psychology. Energy Psychology adalah seperengkat prinsip dan teknik memanfaatkan sistem energi tubuh untuk memperbaiki kondisi pikiran, emosi dan perilaku. SEFT baik digunakan sebagai terapi bagi penderita gangguang cemasan menyeluruh.

Pelaksanaan intervensi menggunakan teknik Spiritual Emotional Freedom Technique (SEFT) pada subjek dilakukan dalam sepuluh sesi pertemuan. Pelaksanaan intervensi dijelaskan sebagai berikut:

1. Pembentukan rapport menggunakan metode observasi dan wawancara. Targetnya adalah adanya hubungan saling percaya (kedekatan) antara subjek dan konselor. Hasil kegiatannya adalah terciptanya hubungan saling percaya (kedekatan) antara subjek dan konselor, selain itu subjek bersedia mengikuti tahapan intervensi.

2. Pengenalan terapi dengan metode Spiritual Emotional Freedom Technique (SEFT) 
menggunakan metode diskusi. Targetnya adalah subjek mengetahui maksud dan tujuan, serta proses dalam melakukan terapi. Hasil kegiatannya adalah subjek mengetahui maksud dan tujuan, serta proses dalam melakukan terapi dengan metode Spiritual Emotional Freedom Technique (SEFT).

3. Pre-test, pengukuran tingkat kecemasan, menjelaskan tentang cara melakukan SEFT menggunakan metode observasi, kuesioner, penyuluhan (ceramah). Targetnya adalah peneliti mengetahui tingkat kecemasan yang dialami subjek sebelum dilakukan terapi, peneliti mengetahui gejala, dan penyebab kecemasan subjek, serta subjek dapat melakukan secara mandiri dan paham dalam melakukan terapi. Hasilnya ialah skor total HARS $=42$, artinya subjek mengalami kecemasan berat sekali. Prosentase kecemasan subjek berada pada angka 8 (dalam range 1-10). Dari hasil pre-test diketahui apa yang dikhawatirkan dan dicemaskan oleh subjek, gejala yang muncul, dan pandangan tentang diri sendiri. Subjek dapat melakukan secara mandiri dan paham dalam melakukan terapi SEFT

4. Memulai terapi dengan metode Spiritual Emotional Freedom Technique (SEFT) dan psikoedukasi menggunakan metode The Set-Up (beberapa kata yang perlu diucapkan dengan penuh perasaan untuk menetralisir Psychological Reversal (keyakinan dan pikiran negatif)), The Tune-In (merasakan rasa sakit yang kita alami, lalu mengarahkan pikiran kita ke tempat rasa sakit, atau memikirkan sesuatu/ peristiwa spesifik tertentu yang dapat membangkitkan emosi negatif yang ingin kita hilangkan dibarengi dengan hati dan mulut kita mengatakan : "Ya Allah saya ikhlas, saya pasrah" atau "Ya Allah saya ikhlas menerima sakit saya ini, saya pasrahkan pada-Mu kesembuhan saya”), The Tapping (mengetuk ringan dengan dua ujung jari pada titik-titik tertentu di tubuh kita sambil terus tune-in). Target saat The Set-Up adalah aliran energi tubuh terarahkan dengan tepat, target saat The Tune-In adalah menetralisir emosi negatif atau rasa sakit fisik, target saat The Tapping adalah ternetralisirnya gangguan emosi atau rasa sakit yang subjek rasakan. Karena aliran energi tubuh berjalan dengan normal dan seimbang kembali. Secara keseluruhan terapi ini memiliki target meredakan kecemasan yang dialami. Hasilnya setelah peneliti menerapkan SEFT pada subjek sesuai dengan tahapannya, subjek merasa lebih lega, tenang, ketegangan mulai berkurang dan lebih dapat berfikir tanpa emosi. Prosentase kecemasan subjek berada pada angka 5 (dalam range 1-10). Subjek lebih memahami mengenai SEFT dan efeknya untuk dirinya (Zainuddin, 2010).

5. Terapi dengan metode Spiritual Emotional Freedom Technique (SEFT) dan psikoedukasi menggunakan metode The Set-Up, The Tune-In, The Tapping. Hasilnya subjek merasa lebih lega, tenang, ketegangan mulai berkurang dan lebih dapat berfikir tanpa emosi. Prosentase kecemasan subjek berada pada angka 4 (dalam range 1-10). Subjek lebih memahami mengenai SEFT dan efeknya untuk dirinya. Dimana Subjek lebih dapat mensyukuri keadaannya saat ini, menerima segala pemberian dari Tuhan, dan ikhlas apapun yang terjadi pada dirinya (Zainuddin, 2010).

6. Psikoedukasi dan penugasan (melakukan SEFT secara mandiri) menggunakan 
metode penyuluhan dan observasi. Targetnya adalah subjek dapat secara mandiri mengaplikasikan teknik SEFT dalam menghadapi kecemasannya, serta memahami fungsi dan tujuan SEFT. Hasilnya subjek lebih memahami mengenai SEFT (fungsi dan tujuan), serta lebih memahami mengenai SEFT (fungsi dan tujuan).

7. Monitoring menggunakan metode wawancara dan observasi. Targetnya adalah subjek mengaplikasikan SEFT secara mandiri di rumah saat gejala kecemasan muncul, serta kecemasan yang dialami subjek mereda. Hasilnya subjek mengaplikasikan SEFT secara mandiri di rumah sebanyak 2 kali.

8. Monitoring menggunakan metode wawancara dan observasi. Targetnya adalah subjek mengaplikasikan SEFT secara mandiri di rumah saat gejala kecemasan muncul, serta kecemasan yang dialaminya mereda. Hasilnya subjek mengaplikasikan SEFT secara mandiri di rumah sebanyak 1 kali.

9. Post-tes dan evaluasi menggunakan metode Observasi, kuesioner, wawancara. Targetnya adalah peneliti mengetahui tingkat kecemasan yang dialami subjek setelah dilakukan terapi (baik dilakukan oleh konselor atau secara mandiri di rumah), peneliti mengetahui efek dari dilakukannya terapi SEFT, kecemasan subjek mereda. Hasilnya skor total HARS $=11$, artinya subjek tidak mengalami kecemasan. Prosentase kecemasan subjek berada pada angka 2 (dalam range 1-10). Subjek menjelaskan bahwa kecemasannya jarang muncul, karena subjek menerapkan SEFT tiap kali kecemasan muncul. Rasa cemas, ketegangan otot dan gangguan fisiologis akibat kecemasan yang muncul, berkurang secara signifikan. Subjek telah menerapkan SEFT sebanyak 4 kali dalam satu minggu. Subjek mengaku merasakan mengantuk, pusing, merasa tenang, lebih percaya diri dan lega setelah melakukan SEFT.

10. Psikoedukasi dan menentukan tidak lanjut menggunakan metode penyuluhan dan diskusi. Targetnya adalah subjek lebih memahami tentang terapi SEFT, serta mampu mengatasi kecemasannya. Hasilnya subjek lebih memahami tentang terapi SEFT dengan mendengarkan penjelasan dari peneliti tentang hasil evaluasi. Dan memberikan bukti-bukti penelitian sebelumnya tentang efek dari terapi SEFT jika dilakukan dengan tepat dan sungguh-sungguh. Subjek mampu mengatasi kecemasannya. Kedepan subjek akan tetap menerapkan SEFT dalam menghadapi kecemasannya.

Pada penelitian ini, teknik Spiritual Emotional Freedom Technique (SEFT) cukup efektif sebagai media untuk meredakan gangguan cemas menyeluruh pada perempuan dewasa. Adapun perubahan perilaku yang signifikan dari sebelum dilakukan intervensi hingga setelah diintervensi, perubahan perilaku tersebut dijelaskan sebagai berikut:

a) Perilaku sebelum diintervensi :

1. Skor total HARS $=42$, artinya subjek mengalami kecemasan berat sekali.

2. Subjek bingung dalam menentukan keputusan yang diambil.

3. Mempersepsikan segala sesuatu negatif baginya. Kekhawatiran akan masa depannya, perasaan bersalah dan menyalahkan diri atas hal yang terjadi pada 
masa lalunya (perselingkuhan, menikah terlalu cepat), munculnya firasat buruk.

4. Ketegangan motorik (gelisah, sakit kepala, gemetaran, tidak dapat santai) lebih sering.

5. Sulit mengontrol emosi.

6. Subjek bingung jika kecemasannya muncul hingga mengganggu fisiknya.

b) Perilaku sesudah diintervensi :

1. Skor total HARS $=11$, artinya subjek tidak mengalami kecemasan.

2. Subjek lebih mampu bersyukur, ikhlas dan pasrah dalam menghadapi permasalahan yang ada dalam hidupnya.

3. Lebih berfikir postif. Subjek lebih dapat menerima keadaan, bersyukur dan ikhlas menjalani kehidupannya. Subjek berusaha memotivasi dirinya agar hidupnya lebih baik dan dapat menikmati hidup.

4. Subjek tidak lagi merasakan ketegangan motorik (gelisah, sakit kepala, gemetaran, tidak dapat santai), bahkan saat ini merasa lebih tenang dan lega.

5. Lebih relaks dan mampu mengontrol emosi.

6. Mampu dalam mengatasi kecemasannya sehingga kecemasan yang dialami saat ini mereda.

\section{Kesimpulan}

Peneliti menggunakan metode Spiritual Emotional Freedom Technique (SEFT) untuk dapat mengurangi atau menghilangkan kecemasan pada subjek. Metode tersebut diajarkan oleh peneliti pada subjek agar subjek mampu secara mandiri melakukan di rumah saat kecemasannya datang.

Setelah dilakukan proses intervensi Spiritual Emotional Freedom Technique (SEFT) pada subjek, didapatkan hasil sementara bahwa subjek tidak lagi mengalami kecemasan karena mampu dalam mengatasi kecemasannya, lebih berfikir positif dan dapat mengontrol emosi. Hal tersebut membuat subjek tidak lagi mengalami gangguan atau sakit secara fisik. Dengan melakukan dan memiliki kemampuan dalam melakukan Spiritual Emotional Freedom Technique (SEFT) secara mandiri, subjek lebih ikhlas, bersyukur dan pasrah, tidak lagi mencemaskan masalalu dan masa depannya. 


\section{BIBILIOGRAFI}

Akbar, Sukma Noor. (2018). Gangguan Kecemasan Menyeluruh Pada Individu Pelaku Pelecehan Seksual. SemNasPsi (Seminar Nasional Psikologi), 1(1), 1-15. Google Scholar

Apriliani, Rizky Ayu. (2015). Pengaruh Yoga Prenatal terhadap kecemasan sesaat dalam menghadapi persalinan pada primigravida trimester III Digalenia Mom and Baby Center Kota Bandung. Fakultas Psikologi (UNISBA). Google Scholar

Blackburn, Ivy Marie, Davidson, Kate, \& Kendell, R. E. (1994). Terapi kognitif untuk depresi dan kecemasan suatu petunjuk bagi praktisi. Alih Bahasa: Rusda Koto Sutadi. Semarang: IKIP Semarang Press. Google Scholar

Diferiansyah, Okta, Septa, Tendry, \& Lisiswanti, Rika. (2016). Gangguan Cemas Menyeluruh. Jurnal Medula, 5(2), 63-68. Google Scholar

Maslim, Rusdi. (2013). Diagnosis gangguan jiwa rujukan ringkas dari PPDGJ-III dan DSM-5. Jakarta: PT Nuh Jaya. Google Scholar

Nevid, Jeffrey S., Rathus, Spencer A., \& Greene, Beverly. (2005). Psikologi abnormal. Jakarta: Erlangga, 96-101. Google Scholar

Reeves, Colin, \& Rowe, Jonathan E. (2002). Genetic algorithms: principles and perspectives: a guide to GA theory (Vol. 20). Springer Science \& Business Media. Google Scholar

Rofacky, Hendri Fajri, \& Aini, Faridah. (2015). Pengaruh Terapi Spiritual Emotional Freedom Technique (SEFT) terhadap Tekanan Darah Penderita Hipertensi. Jurnal Keperawatan Soedirman, 10(1), 41-52. Google Scholar

Rowe, Jack E. (2005). The Effects of EFT on Long-Term Psychological Symptoms. Counseling \& Clinical Psychology Journal, 2(3). Google Scholar

Siyoto, Sandu, \& Sodik, Muhammad Ali. (2015). Dasar metodologi penelitian. Literasi Media Publishing. Google Scholar

Sugiyono, Prof. (2015). Metode penelitian kombinasi (mixed methods). Bandung: Alfabeta, 28. Google Scholar

Suherni; Hidayati, F., MA. (2017). Selangkah Lebih Sehat Dengan Terapi Spiritual Emotional Freedom Technique (SEFT). Skripsi. Fakultas Psikologi Universitas Islam Negeri Maulana Malik Ibrahim Malang.

Zainuddin, Ahmad Faiz. (2006). Spiritual emotional freedom technique (SEFT). Jakarta: Afzan Publishing. Google Scholar 
Karina Kandhi Krisnawardhani dan IGAA Noviekayati

\section{Copyright holder:}

Karina Kandhi Krisnawardhani dan IGAA Noviekayati (2021)

First publication right:

Journal Syntax Literate

This article is licensed under:

(c) $\oplus \ominus$ 